\title{
Dietary intake of eicosapentaenoic acid (EPA) and docosahexaenoic acid (DHA) in children - a workshop report
}

\author{
Berthold Koletzko $^{1 *}$, Ricardo Uauy ${ }^{2,3}$, Andreu Palou ${ }^{4,5}$, Frans Kok $^{6}$, Gerard Hornstra ${ }^{7}$, Ans Eilander ${ }^{8}$, \\ Diego Moretti ${ }^{8}$, Saskia Osendarp ${ }^{8}$, Peter Zock ${ }^{8}$ and Sheila Innis ${ }^{9}$ \\ ${ }^{1}$ Division of Metabolic Diseases and Nutrition, Dr von Hauner Children's Hospital, University of Munich Medical Centre, \\ Lindwurmstrasse 4, D-80337 Munich, Germany \\ ${ }^{2}$ Public Health Nutrition, London School of Hygiene and Tropical Medicine, London, UK \\ ${ }^{3}$ Institute of Nutrition and Food Technology (INTA), University of Chile, Santiago, Chile \\ ${ }^{4}$ Laboratory of Molecular Biology, Nutrition and Biotechnology, Universitat de les Illes Balears, Palma de \\ Mallorca, Spain \\ ${ }^{5}$ CIBER Fisiopatología de la Obesidad y Nutrición (CB06/03) (Instituto de Salud Carlos III), Palma de \\ Mallorca, Spain \\ ${ }^{6}$ Division of Human Nutrition, Wageningen University, Wageningen, The Netherlands \\ ${ }^{7}$ Nutrition and Toxicology Research Institute Maastricht, Maastricht University, Maastricht, The Netherlands \\ ${ }^{8}$ Unilever Food and Health Research Institute, Unilever R\&D, Vlaardingen, The Netherlands \\ ${ }^{9}$ Department of Paediatrics, University of British Columbia, Vancouver, BC, Canada
}

(Received 10 June 2009 - Revised 4 August 2009 - Accepted 5 August 2009 - First published online 26 February 2010)

\begin{abstract}
There is controversy whether children should have a dietary supply of preformed long-chain polyunsaturated $n$ - 3 fatty acids EPA and DHA. The aims of the workshop were to review evidence for a possible benefit of a preformed EPA and/or DHA supply, of data required to set desirable intakes for children aged 2-12 years, and of research priorities. The authors concluded that EPA and DHA intakes per kg body weight may often be low in 2- to 12-year-old children, relative to intakes per kg body weight of breast-fed infants and adult intakes, but reliable data are scarce. Little information is available that increasing dietary intakes of EPA or DHA in children has benefits to physical or mental function or other health endpoints. Studies addressing EPA and DHA intakes and tissue status among groups of children with different dietary habits, and measures of relevant development and health endpoints, are needed for developing potential advice on desirable intakes of EPA and/or DHA in children. At this time it appears prudent to advise that dietary intakes in childhood are consistent with future eating patterns supporting adult health, such as prevention of metabolic disorders and CVD, supporting immune function, and reproductive health. In conclusion, the available information relating dietary EPA and DHA intakes in children aged 2-12 years to growth, development and health is insufficient to derive dietary intake recommendations for EPA and DHA. Adequately designed studies addressing dietary intakes, measures of status and relevant functional or health effects across this age group are needed.
\end{abstract}

EPA: DHA: $n$-3 Long-chain PUFA: Reference nutrient values: RDA

Several national and international organisations have provided guidance on desirable dietary intakes of the long-chain PUFA DHA and EPA from fish for adults and for infants (Table 1). For adults, these recommendations are based mainly on primary and secondary prevention of CVD, ranging from one to two portions of fatty fish per week or about $500 \mathrm{mg}$ EPA and DHA per $\mathrm{d}^{(1,2)}$. For pregnant and lactating women, the advice of an average daily intake of at least $200 \mathrm{mg}$ DHA is based on optimal pregnancy outcomes ${ }^{(3-5)}$, and on possible beneficial effects on fetal and infant development ${ }^{(6,7)}$. For infants (0-2 years of age), in 1994, the FAO/WHO ${ }^{(8)}$ recommended $20 \mathrm{mg}$ DHA per $\mathrm{kg}$ body weight per $\mathrm{d}$ for optimal growth and development. However, there are no agreed recommendations for the advisable dietary intake of EPA and/or DHA for children above 2 years of age.

A workshop was organised in July 2007 to review and discuss the available evidence on dietary intakes of EPA and DHA and their potential physiological relevance to growth and health in children, and to evaluate whether there are sufficient scientific data for issuing evidence-based guidelines on EPA and DHA intake in 2- to 12-year-old children. The present paper summarises the outcomes of the discussions held at the workshop on current knowledge of dietary intakes among children 2-12 years of age and published literature 
Table 1. Recommendations for daily intake of DHA and EPA in adults and infants

\begin{tabular}{|c|c|c|}
\hline Institution & Adults & Infants \\
\hline FAO/WHO (1994) $)^{(8)}$ & - & $20 \mathrm{mg} \mathrm{DHA} / \mathrm{kg} \mathrm{BW}$ \\
\hline $\begin{array}{l}\text { Agence Française de Sécurité Sanitaire } \\
\text { des Aliments \& CNERNA-CNRS }{ }^{(49)}\end{array}$ & $\begin{array}{l}\text { DHA: } 0.05 \% \text { energy } \\
\text { Men: } 120 \mathrm{mg} \text { DHA } \\
\text { Women: } 100 \mathrm{mg} \mathrm{DHA}\end{array}$ & - \\
\hline Health Council of The Netherlands ${ }^{(50)}$ & $200 \mathrm{mg} E P A+D H A$ & $20 \mathrm{mg} \mathrm{DHA} / \mathrm{kg} \mathrm{BW}$ \\
\hline $\begin{array}{l}\text { European Commission Directorate General } \\
\quad \text { for Health and Consumer Protection }(\text { Unit } F / 3)^{(51)}\end{array}$ & $200 \mathrm{mg} E P A+D H A$ & - \\
\hline WHO $(2003)^{(52)}$ & $\begin{array}{l}400-1000 \mathrm{mg} \text { EPA + DHA as one } \\
\text { or two portions fish per week }\end{array}$ & - \\
\hline UK Scientific Advisory Committee on Nutrition ${ }^{(53)}$ & $\begin{array}{l}\text { Assumes } 450 \mathrm{mg} \text { EPA }+ \text { DHA as } \\
\text { two portions fish per week }\end{array}$ & - \\
\hline $\begin{array}{l}\text { International Society for the Study of Fatty } \\
\text { Acids and Lipids }(2004)^{(54)}\end{array}$ & $>500 \mathrm{mg} \mathrm{EPA}+\mathrm{DHA}$ & - \\
\hline Conseil Supérieur d'Hygiène, Service Public & $>0.3 \%$ energy & EPA: $0.05-0.15 \%$ energy \\
\hline Fédéral de la Santé Publique, Belgium ${ }^{(55)}$ & $670 \mathrm{mg} E P A+D H A$ & DHA: $0.10-0.40 \%$ energy \\
\hline Deutsche Gesellschaft für Ernährung $(2005)^{(56)}$ & $250 \mathrm{mg} E P A+D H A$ & - \\
\hline Consensus recommendation ${ }^{*(6)}$ & $\geq 200 \mathrm{mg} \mathrm{DHA}$ during pregnancy and lactation & - \\
\hline $\begin{array}{l}\text { Position of the American Dietetic Association } \\
\text { and Dietitians of Canada }\end{array}$ & $500 \mathrm{mg}$ EPA + DHA & - \\
\hline
\end{tabular}

BW, body weight; CNERNA-CNRS, Centre Nationale d'Etudes et de Recommendations sur la Nutrition et l'Alimentation \& Centre National de la Recherche Scientifique; AA, arachidonic acid.

* Supported by Perinatal Lipid Nutrition Project, Early Nutrition Programming Project, Child Health Foundation, Diabetic Pregnancy Study Group, European Association of Perinatal Medicine, European Society for Clinical Nutrition and Metabolism, European Society for Paediatric Gastroenterology, Hepatology and Nutrition, International Federation of Placenta Associations, and International Society for the Study of Fatty Acids and Lipids.

regarding the potential importance of EPA and DHA at this stage of the life cycle.

\section{EPA and DHA intakes in children}

The richest food sources of both EPA and DHA are fatty fish, with smaller amounts in lean fish and other seafood ${ }^{(9,10)}$. The distributions of dietary EPA and DHA intakes within populations are generally skewed with lower median than mean intakes, explained by a substantial number of individuals eating no or very little fish ${ }^{(10-12)}$. However, information of dietary intakes of EPA and DHA, particularly among children, is limited. This has several reasons, including the limitations of dietary intake methodology, collecting accurate information on dietary intakes from children, and the completeness of fatty acid data on foods listed in databases. For example, the fat and fatty acid composition of fish varies widely, meaning that specific information on the types of fish and seafood consumed is essential; eggs can be an important source of fatty acids and are often hidden in other foods such as cakes and puddings, but depending on the recall method their intake may be missed. Moreover, children frequently consume food outside of the home, and without the parents' knowledge.

The rather limited available information on dietary intake in children suggests that EPA and DHA intake tends to be lower than in adults ${ }^{(13)}$. Similarly, the intake of children may also be lower per kg body weight than in infants who are breast-fed or fed infant formulas containing $\mathrm{DHA}^{(7,14)}$. Children's current dietary intake of EPA and DHA may also be lower than some decades ago ${ }^{(15)}$. Whether current intakes of EPA and DHA among children are adequate for optimal functional and health outcomes requires information on dietary intakes of children following different diets together with measures of functional endpoints sensitive to potential biological effects of these fatty acids. It is conceivable that EPA and/ or DHA intakes might contribute to health promotion and chronic disease prevention, but reliable and comparable data on dietary intake of $n-3$ fatty acids and on biochemical markers of status in different populations of children are scarce. The available data do not allow us to conclude that changing intakes of EPA and/or DHA can affect physical or mental development or yield specific functional benefits.

\section{The effects of EPA and DHA on biological function, health and prevention of disease}

Historically, recommended intake levels for nutrients have been defined to prevent signs of deficiency in the general population. In recent years, however, nutritional recommendations and guidelines are being progressively formulated based on evidence linking specific nutrients at given intakes to disease prevention and optimal performance and health $^{(16)}$. An example is the Acceptable Macronutrient Distribution Range used by the Institute of Medicine ${ }^{(17)}$, which represents the range of energy intakes from the different macronutrient intakes that, when consumed as part of a diet providing an appropriate amount of energy to maintain ideal body weight, are associated with low risk of chronic disease.

Individuals that have low EPA and/or DHA intakes but eat plentiful sources of $\alpha$-linolenic acid, such as vegans and vegetarians, do have a lower EPA and DHA status than omnivores, but are not known to develop signs of deficiency ${ }^{(18)}$. 
Higher intake levels of EPA and DHA have been associated with a range of possible physiological and health benefits in humans ${ }^{(19)}$, such as the improvement in neurological functions in infancy ${ }^{(20)}$, the primary and secondary prevention of CVD and the metabolic syndrome in adults ${ }^{(1,21)}$, modulation of immune response ${ }^{(22)}$ and improved pregnancy outcomes ${ }^{(3-5)}$. The evidence for beneficial effects of EPA and DHA intakes on health outcomes in children is limited and will be summarised here.

The importance of attaining optimal brain and retina DHA for visual and neurological development and function is considered critical in the perinatal period ${ }^{(23)}$. Beyond infancy, evidence linking DHA intake or blood levels of DHA with neurological benefits is limited to children following restricted diets with very low dietary intakes of EPA and DHA, such as children with phenylketonuria ${ }^{(24-26)}$. These studies show that increasing DHA status with fish oil supplements is consistent with improvements in speed of information processing in the central nervous system as assessed by latencies of visual evoked potentials ${ }^{(24)}$, as well as significant improvements of coordination and fine motor skills ${ }^{(25)}$. These findings indicate that a continuous dietary supply of preformed DHA and/or EPA may be essential for achieving optimal neural function even in children who have a high intake of the precursor $\alpha$-linolenic acid with restricted diets due to phenylketonuria ${ }^{(27)}$. This conclusion may be relevant for healthy children as well, since children with early treated phenylketonuria are generally healthy and have no detectable alterations of energy and fatty acid metabolism.

EPA and DHA in combination with $n-6$ fatty acids have also been reported to improve behaviour in children with neurodevelopmental disorders such as attention-deficit hyperactivity disorder and dyspraxia in some ${ }^{(28-30)}$ but not all $^{(31,32)}$ studies. A recent systematic review of these studies concluded that there is insufficient evidence to identify any effect of nutrition, diet and dietary change on learning, education or performance of school-aged children from the developed world ${ }^{(33)}$. Further research of high quality, representative of all populations, undertaken for longer durations and using universal standardised measures of educational attainment is needed ${ }^{(33)}$ and should evaluate the potential relative roles of EPA and DHA, respectively, in children with neurodevelopmental disorders.

High intakes of EPA and/or DHA may beneficially modulate the immune system by decreasing the synthesis of pro-inflammatory arachidonic acid-derived eicosanoids ${ }^{(34)}$ and by shifting the balance of $\mathrm{T}$ helper 1 (Th1), $\mathrm{T}$ helper 2 (Th2) and $\mathrm{T}$ regulatory cells ${ }^{(35)}$. Evidence for beneficial effects on asthma in children is not established, but some studies suggested that for certain subgroups of respondent children, symptoms of asthma may be alleviated with DHA/ EPA supplementation ${ }^{(36)}$. It is unclear to what extent these and other observations using high dosages of EPA and DHA supplements relate to possible effects with lower intakes achieved with foods.

A regular intake of fatty fish is widely advised to adult populations for the prevention of CVD, and a large part of associated beneficial effects is thought to be mediated by the supply of EPA and DHA with fatty fish ${ }^{(1)}$. Potential beneficial effects of EPA and DHA intakes in children on their future risk of developing CVD have not been documented. However, food preferences and eating habits that are established in childhood appear to show a certain degree of tracking into adulthood $^{(37,38)}$. Therefore, it seems desirable to accustom children to dietary patterns that are likely to promote health in adulthood.

\section{Approaches to develop possible advice on dietary intakes of EPA and DHA}

Advice on dietary nutrient intake values for children is based on a variety of different methodological approaches, including consideration of deficiency states, usual intake levels, factorial approaches to calculate needs for maintenance and growth, effects on physiological function and health ${ }^{(39)}$ and extrapolation from reference values established for other age groups such as adults or infants ${ }^{(40)}$. The authors of the present paper conclude that the current lack of reliable data on the relationship between EPA and DHA intake or status and functional and health outcomes in 2- to 12-year-old children does not allow determination of physiological requirements or nutrient intake levels using classical approaches to derive dietary recommendations. Extrapolating $n-3$ fatty acid intake levels, including those for EPA and DHA, for children from existing reference values for either adults or infants (Table 1) seems inappropriate, not only because there is still considerable uncertainty regarding nutrient intake levels for DHA and/or EPA in both adults and infants, but also because extrapolation based for example on body mass or energy expenditure is expected to inadequately reflect age-specific physiological requirements, such as continuing neurological development and lean tissue growth, that determine dietary nutrient needs ${ }^{(40)}$. Thus, at present the available evidence is insufficient to formulate quantitative nutrient intake values for EPA and DHA in children. However, it seems reasonable that dietary advice for children should be consistent with advice for the adult population, such as regular intake of one to two fatty fish meals per week providing DHA and EPA associated with the risk reduction of CVD. If such a habit can be established early in life and be maintained, it may also support a desirable long-chain $n$-3 fatty acid supply among females of child-bearing age to support optimal pregnancy outcomes. There is no reason why children in a family setting should be excluded from the consumption of at least one to two meals of fatty fish per week, which is recommended for the adult population ${ }^{(2)}$.

\section{Present and future research}

The possible relationships between intake and effects of DHA and/or EPA need to be studied in detail. Presently, the research project 'Nutrition and Mental Health' funded by the European Commission's 7th Framework Research Programme will try to establish whether there is a relationship between the level of dietary DHA supply and neurological functions in children. Further studies should also include evaluating effects of the intake of $\alpha$-linolenic acid, as well as factors affecting its endogenous conversion to EPA and DHA, such as the concomitant intake of linoleic acid $^{(41)}$ and the role of genetic polymorphisms of the desaturating enzymes $\Delta-6$ and $\Delta-5$ desaturases $^{(42)}$. 
Relevant public health outcomes that are likely to be linked to lifelong intakes of EPA and DHA include the risk of (future) CVD and the metabolic syndrome, optimal mental development and behaviour, and immune response.

Dietary studies should be carefully conducted and analysed, with a specific and standardised methodology, considering the substantial challenges in assessing individual intakes of EPA and DHA in children. Since assessment methods for dietary intake are imprecise, age-specific information on fatty acid status based on biological markers are also required. Cross-sectional analyses from prospective birth and childhood cohort studies are likely to provide valuable insights that can contribute to designing intervention trials. Age-specific effects of different fatty acid intakes and dosages on relevant endpoints should be assessed in controlled intervention studies. The data obtained should aim at establishing the effect of different doses of individual fatty acids, and of different combinations and ratios of PUFA, on well-defined and quantifiable outcomes. Such outcomes may include:

(1) Markers of cardiovascular risk and the metabolic syndrome;

(2) Measures of neural function, cognition and behaviour;

(3) Markers of inflammatory response, immune function and their related diseases, such as allergy or autoimmune disease.

Studies in children aiming at evaluating these and other outcomes must respect the limitations determined by the ethical rules for research with children ${ }^{(43,44)}$.

Although recent risk analyses tend to support the safety and overall benefit of increased fish consumption ${ }^{(45,46)}$, potential adverse effects of recommending increased dietary intakes of EPA and DHA from fish oil concentrates or fatty fish, such as the risk of adverse effects of contamination with environmental pollutants ${ }^{(47,48)}$, should be taken into account.

\section{Conclusions}

A better understanding of the functional roles of EPA and DHA in children is required in order to determine adequate dietary intakes. Currently there is a lack of sufficient evidence to link levels of dietary intake of DHA and/or EPA to improved physical, mental or other functional benefits in children. Therefore, quantitative dietary intake recommendations for children cannot be established at this time.

Food-based dietary guidelines that apply to adults for enhancing health and preventing chronic diseases such as CVD will usually apply to the whole population, including children, unless there are specific arguments for alternative guidelines or recommendations. There is no reason why children should be excluded from the advice to consume at least one to two meals of fatty fish per week as recommended for adults. Establishing a quantitative dietary intake recommendation for EPA and DHA for children aged 2-12 years will require a research programme focusing on welldefined, public health-relevant and age-specific outcomes in this specific age group.

\section{Acknowledgements}

All authors reviewed and discussed the available evidence on dietary intakes of EPA and DHA and agreed on the conclusions at the workshop held in July 2007. B. K., A. E., D. M. and S. I. wrote the first draft of the manuscript. All authors reviewed and contributed to the revision of the manuscript.

S. O., D. M., A. E. and P. Z. are employees of Unilever. Unilever markets foods, among which products rich in $n-3$ fatty acids. Unilever Food and Health Research Institute organised and funded the workshop attended by all authors.

Research by B. K. on functional effects of EPA and DHA has been carried out with partial financial support from the Commission of the European Communities, within the 7th Framework Programme, contract no. FP7-212652. This paper does not necessarily reflect the views of the Commission and in no way anticipates future policy in this area.

B. K. and S. I. are recipients of Freedom-to-Discover Awards of the Bristol-Myers-Squibb Foundation (New York, NY, USA).

R. U. was President of the International Union of Nutrition Sciences (IUNS), he does not receive personal income from Unilever, his research funding comes from the Wellcome Trust and the Chilean Council for Scientific and Technological Development; he declares no conflicting interests relative to the content of this paper.

\section{References}

1. Mozaffarian D \& Rimm EB (2006) Fish intake, contaminants, and human health: evaluating the risks and the benefits. JAMA 296, 1885-1899.

2. Kris-Etherton PM \& Innis S (2007) Position of the American Dietetic Association and Dietitians of Canada: dietary fatty acids. J Am Diet Assoc 107, 1599-1611.

3. Szajewska H, Horvath A \& Koletzko B (2006) Effect of $n-3$ long-chain polyunsaturated fatty acid supplementation of women with low-risk pregnancies on pregnancy outcomes and growth measures at birth: a meta-analysis of randomized controlled trials. Am J Clin Nutr 83, 1337-1344.

4. Horvath A, Koletzko B \& Szajewska H (2007) Effect of supplementation of women in high-risk pregnancies with longchain polyunsaturated fatty acids on pregnancy outcomes and growth measures at birth: a meta-analysis of randomized controlled trials. Br J Nutr 98, 253-259.

5. Makrides M, Duley L \& Olsen SF (2006) Marine oil, and other prostaglandin precursor, supplementation for pregnancy uncomplicated by pre-eclampsia or intrauterine growth restriction. The Cochrane Database of Systematic Reviews 2006, issue 3, CD003402. http://www.mrw.interscience.wiley.com/cochrane/ clsysrev/articles/CD003402/frame.html

6. Koletzko B, Cetin I \& Brenna JT (2007) Dietary fat intakes for pregnant and lactating women. Br J Nutr 98, 873-877.

7. Koletzko B, Lien E, Agostoni C, et al. (2008) The roles of longchain polyunsaturated fatty acids in pregnancy, lactation and infancy: review of current knowledge and consensus recommendations. J Perinat Med 36, 5-14.

8. Food and Agriculture Organization \& World Health Organization (1994) Fats and Oils in Human Nutrition. FAO Food and Nutrition Paper no. 57. Rome: FAO.

9. Innis SM \& Elias SL (2003) Intakes of essential $n-6$ and $n-3$ polyunsaturated fatty acids among pregnant Canadian women. Am J Clin Nutr 77, 473-478. 
10. Meyer BJ, Mann NJ, Lewis JL, et al. (2003) Dietary intakes and food sources of omega- 6 and omega-3 polyunsaturated fatty acids. Lipids 38, 391-398.

11. Astorg P, Arnault N, Czernichow S, et al. (2004) Dietary intakes and food sources of $n-6$ and $n-3$ PUFA in French adult men and women. Lipids 39, 527-535.

12. Welch AA, Lund E, Amiano P, et al. (2002) Variability of fish consumption within the 10 European countries participating in the European Investigation into Cancer and Nutrition (EPIC) study. Public Health Nutr 5, 1273-1285.

13. United States Department of Agriculture Agricultural Research Service (2007) Nutrient Intakes from Food: Mean Amounts Consumed per Individual, One Day, 2003-2004. http://www.ars.usda.gov/SP2UserFiles/Place/12355000/pdf/0506/ Table_2_NIF_05.pdf

14. Koletzko B, Rodriguez-Palmero $\mathrm{M}$, Demmelmair $\mathrm{H}$, et al. (2001) Physiological aspects of human milk lipids. Early Hum Dev 65, Suppl., S3-S18.

15. Ailhaud G, Massiera F, Weill P, et al. (2006) Temporal changes in dietary fats: role of $n-6$ polyunsaturated fatty acids in excessive adipose tissue development and relationship to obesity. Prog Lipid Res 45, 203-236.

16. World Health Organization \& Food and Agriculture Organization (2004) Vitamin and Mineral Requirements in Human Nutrition. Joint FAO/WHO Expert Consultation on Human Vitamin and Mineral Requirements. Geneva: WHO/FAO.

17. Institute of Medicine (2005) Dietary Reference Intakes for Energy, Carbohydrate, Fiber, Fat, Fatty Acids, Cholesterol, Protein, and Amino Acids (Macronutrients). Washington, DC: The National Academies Press.

18. Davis BC \& Kris-Etherton PM (2003) Achieving optimal essential fatty acid status in vegetarians: current knowledge and practical implications. Am J Clin Nutr 78, 640S-646S.

19. Akabas SR \& Deckelbaum RJ (2006) Summary of a workshop on $n-3$ fatty acids: current status of recommendations and future directions. Am J Clin Nutr 83, 1536S-1538S.

20. Cheatham CL, Colombo J \& Carlson SE (2006) n-3 Fatty acids and cognitive and visual acuity development: methodologic and conceptual considerations. Am J Clin Nutr 83, 1458S-1466S.

21. Carpentier YA, Portois L \& Malaisse WJ (2006) n-3 Fatty acids and the metabolic syndrome. Am J Clin Nutr 83, 1499S-1504S.

22. Sijben JWC \& Calder PC (2007) Differential immunomodulation with long-chain $n$-3 PUFA in health and chronic disease. Proc Nutr Soc 66, 237-259.

23. Eilander A, Hundscheid DC, Osendarp SJ, et al. (2007) Effects of $n-3$ long chain polyunsaturated fatty acid supplementation on visual and cognitive development throughout childhood: a review of human studies. Prostaglandins Leukot Essent Fatty Acids 76, 189-203.

24. Beblo S, Reinhardt H, Muntau AC, et al. (2001) Fish oil supplementation improves visual evoked potentials in children with phenylketonuria. Neurology 57, 1488-1491.

25. Beblo S, Reinhardt H, Demmelmair H, et al. (2007) Effect of fish oil supplementation on fatty acid status, coordination, and fine motor skills in children with phenylketonuria. J Pediatr 150, 479-484.

26. Agostoni C, Massetto N, Biasucci G, et al. (2000) Effects of long-chain polyunsaturated fatty acid supplementation on fatty acid status and visual function in treated children with hyperphenylalaninemia. J Pediatr 137, 504-509.

27. Agostoni C, Verduci E, Massetto N, et al. (2003) Long term effects of long chain polyunsaturated fats in hyperphenylalaninemic children. Arch Dis Child 88, 582-583.

28. Stevens L, Zhang W, Peck L, et al. (2003) EFA supplementation in children with inattention, hyperactivity, and other disruptive behaviors. Lipids 38, 1007-1021.
29. Richardson AJ \& Puri BK (2002) A randomized double-blind, placebo-controlled study of the effects of supplementation with highly unsaturated fatty acids on ADHD-related symptoms in children with specific learning difficulties. Prog Neuropsychopharmacol Biol Psychiatry 26, 233-239.

30. Richardson AJ \& Montgomery P (2005) The Oxford-Durham study: a randomized, controlled trial of dietary supplementation with fatty acids in children with developmental coordination disorder. Pediatrics 115, 1360-1366.

31. Hirayama S, Hamazaki T \& Terasawa K (2004) Effect of docosahexaenoic acid-containing food administration on symptoms of attention-deficit/hyperactivity disorder - a placebocontrolled double-blind study. Eur J Clin Nutr 58, 467-473.

32. Voigt RG, Llorente AM, Jensen CL, et al. (2001) A randomized, double-blind, placebo-controlled trial of docosahexaenoic acid supplementation in children with attention-deficit/hyperactivity disorder. J Pediatr 139, 189-196.

33. Ells LJ, Hillier FC \& Summerbell CD (2007) A Systematic Review of the Effect of Nutrition, Diet and Dietary Change on Learning, Education and Performance of Children of Relevance to UK Schools. Middlesbrough, UK: University of Teesside, School of Health \& Social Care, Centre for Food, Physical Activity and Obesity Research.

34. Calder PC (2006) n-3 Polyunsaturated fatty acids, inflammation, and inflammatory diseases. Am J Clin Nutr 83, 1505S-1519S.

35. Krauss-Etschmann S, Hartl D, Rzehak P, et al. (2008) Decreased cord blood IL-4, IL-13, and CCR4 and increased TGF- $\beta$ levels after fish oil supplementation of pregnant women. J Allergy Clin Immunol 121, 464-470.

36. Nagakura T, Matsuda S, Shichijyo K, et al. (2000) Dietary supplementation with fish oil rich in omega-3 polyunsaturated fatty acids in children with bronchial asthma. Eur Respir $J$ 16, $861-865$.

37. Parsons TJ, Manor O \& Power C (2006) Physical activity and change in body mass index from adolescence to mid-adulthood in the 1958 British cohort. Int J Epidemiol 35, 197-204.

38. Lanigan J, Turnbull B \& Singhal A (2007) Toddler diets in the UK: deficiencies and imbalances. 2. Relationship of toddler diet to later health. J Fam Health Care 17, 197-200.

39. Prentice A, Branca F, Decsi T, et al. (2004) Energy and nutrient dietary reference values for children in Europe: methodological approaches and current nutritional recommendations. Br J Nutr 92, Suppl. 2, S83-S146.

40. Atkinson SA \& Koletzko B (2007) Determining lifestage groups and extrapolating nutrient intake values (NIVs) Food Nutr Bull 28, S61-S76.

41. Blank C, Neumann MA, Makrides M, et al. (2002) Optimizing DHA levels in piglets by lowering the linoleic acid to $\alpha$-linolenic acid ratio. J Lipid Res 43, 1537-1543.

42. Schaeffer L, Gohlke H, Muller M, et al. (2006) Common genetic variants of the FADS1 FADS2 gene cluster and their reconstructed haplotypes are associated with the fatty acid composition in phospholipids. Hum Mol Genet 15, 1745-1756.

43. Ungar D, Joffe S \& Kodish E (2006) Children are not small adults: documentation of assent for research involving children. $J$ Pediatr 149, S31-S33.

44. Knudson PL (2002) Research with children. Arch Med Res 33, 203-204.

45. Cohen JT, Bellinger DC, Connor WE, et al. (2005) A quantitative risk-benefit analysis of changes in population fish consumption. Am J Prev Med 29, 325-334.

46. Sioen I, De HS, Verbeke W, et al. (2008) Fish consumption is a safe solution to increase the intake of long-chain n-3 fatty acids. Public Health Nutr 11, 1107-1116.

47. Oken E, Radesky JS, Wright RO, et al. (2008) Maternal fish intake during pregnancy, blood mercury levels, and child cognition at age 3 years in a US cohort. Am J Epidemiol 167, 1171-1181. 
48. Halldorsson TI, Meltzer HM, Thorsdottir I, et al. (2007) Is high consumption of fatty fish during pregnancy a risk factor for fetal growth retardation? A study of 44824 Danish pregnant women. Am J Epidemiol 166, 687-696.

49. Agence Française de Sécurité Sanitaire des Aliments, Centre Nationale d'Etudes et de Recommendations sur la Nutrition et l'Alimentation \& Centre National de la Recherche Scientifique (2001) Apports Nutritionnels Conseilles pour la Population Française (Dietary Advice for the French Population), 3rd ed. Paris: Editions Tec \& Doc.

50. Health Council of The Netherlands (2001) Dietary Reference Intakes: Energy, Proteins, Fats, and Digestible Carbohydrates, publication no. 2001/19. The Hague: Health Council of The Netherlands.

51. Rajala M (2001) Nutrition and diet for healthy lifestyles in Europe: science and policy implications. Public Health Nutr 4, 339-340.
52. World Health Organization (2003) Diet, Nutrition and the Prevention of Chronic Diseases. Joint WHO/FAO Expert Consultation. WHO Technical Report Series no. 916. Geneva: WHO.

53. UK Scientific Advisory Committee on Nutrition (2004) Advice on Fish Consumption: Benefits and Risks. London: The Stationery Office.

54. Cunnane SC, Drevon CA, Harris B, et al. (2004) Recommendations for Intake of Polyunsaturated Fatty Acids in Healthy Adults. Tiverton, UK: International Society for the Study of Fatty Acids and Lipids.

55. Brasseur D, Delzenne N, Henderickx H, et al. (2004) Recommandations et Allégations Concernant les Acides Gras Oméga-3 (Recommendations and Claims Concerning Omega-3 Fatty Acids). Brussels: Conseil Supérieur d'Hygiène.

56. Deutsche Gesellschaft für Ernährung (German Nutrition Society) (2005) Nutrition Report 2004. Bonn: DGE. 